\title{
Multilingualism in a global village: What is the future of a local language (e.g. Northern Sotho) in an increasingly globalized world?
}

\author{
P. Phaahla \\ Department of African Languages, University of South Africa \\ P.O. Box 392, UNISA 0003, Pretoria, South Africa \\ pphaahla@unisa.ac.za
}

\begin{abstract}
South Africa is currently occupying a precarious position within a framework of globalization and internationalization where cultural and linguistic pluralism prevail. There is divergence between South Africa's multilingual language policy on the one hand, and its language practices on the other. Although South Africa is in its 16th year of democracy, people are still grappling with issues such as the financial costs of using more than one official language in commerce and industry. It is argued that it is extremely costly to change letterheads and logos of companies in an attempt to align them with the languages of the country, a notion that does not take into cognisance the reality of South Africa as a multilingual country. The idea expressed is that using some of the 11 official languages and sign language in parallel will be contingent to practicality and expense.
\end{abstract}

The purpose of this article is twofold. First, it seeks to determine whether a balance can be maintained between the global need to communicate and the need to preserve local and regional identities and cultures. Secondly, it endeavours to establish whether it is feasible in South Africa, to maintain the prospects of multilingualism on the one hand and to simultaneously promote the use of the local indigenous languages on the other, in an increasingly globalized world. A previous study, which established the feasibility of using a language of limited diffusion (e.g. Northern Sotho) as a language of commerce and industry, will be a case in point. The article will further determine the apposite environment as an enabler for employing Northern Sotho as a language of marketing, advertising and business. Language practices in the sectors of organic financial growth in South Africa are also explored.

\section{Introduction}

To assess the position of multilingualism in South Africa and the future of the local languages in an increasingly globalized world, the following questions need to be addressed:

- Is there a move toward the use of a single language for global communication, or are there ways of managing language diversity at the international level?

- Can a balance be maintained between the global need to communicate and the need to preserve local and regional identities and cultures?

- What are the roles of education, of language rights, and of language equality in this volatile global linguistic $\operatorname{mix}$ ?

An overview of languages of the world shows that there is a huge disparity between the mean size of languages and the median size. It turns out that approximately $5 \%$ of the world's languages have at least one million speakers and account for $94 \%$ of the world's population. By contrast, the remaining $95 \%$ of languages are spoken by only $6 \%$ of the world's population (Gordon, 2005:7).

The Internet (worldwide communication network) reveals that English is used with the highest frequency on the Internet at $30.6 \%$, followed by Chinese. This is in contrast with the languages of the world with the most speakers among which English ranks as the fourth, according to Ethnologue, fifteenth edition.

In view of the unprecedented wave of globalization sweeping the world today, the sophistication of local black languages should be significantly stepped up from their normal range of mundane discourse to an economic discourse. 
This would facilitate the process of mother-tongue speakers taking charge of their languages and competing locally in terms of being generally innovative and competent in the domain of business, assuming that a newfound confidence will expand their language use and make knowledge readily accessible for trade and business purposes. Knowledge production is inaccessible to most indigenous people in South Africa but accessible to a few who are proficient in English. The use of indigenous languages will enable these ordinary people to grasp economic concepts and demonstrate what they have mastered intellectually in a language with which they are familiar.

The question is: Can a balance be struck between the global need to communicate internationally and the preservation of local and regional identities and cultures? With the view to answering this question, the researcher investigated the feasibility of using a regional language of limited diffusion (LLD) such as Northern Sotho as a language of commerce and industry. ${ }^{1}$

\section{Language 'rights'}

The perception that language 'rights' are about the redress of past wrongs has had negative effects on efforts to gain broad public support for the teaching and maintenance of languages other than English in most countries, notably the USA (Ricento, 2005:349). Ruiz (1984:27) notes on the one hand that while a resource orientation in language planning is not without its problems, a 'fuller development of a resource-oriented approach to language planning could help to reshape attitudes about language and language groups'. Ricento (2005:356) on the other hand views the language-as-resource orientation as not ascribing lower status to heritage languages but giving marginal recognition to essentially unquantifiable resources associated with languages (e.g. psychological, cultural affiliation, aesthetic, and historical aspects).

In the light of the above, Ruiz (1984:27) contends that a language-as-resource orientation is an alternative to a language-rights approach; hence an emerging polity such as South Africa had to adopt both orientations in its language planning strategy so that the two orientations can complement each other but regards its legal context as essential to language development.

Equality of language rights in South Africa is guaranteed by the fact that these rights fall under individual human rights. These individual rights ensure equality for all and non-discrimination against any person wishing to exercise those rights.

\section{Language as an economic resource}

Viewing language as a resource or as an economic resource underlines the importance to the nation of conserving and developing all its linguistic resources. According to Ricento (2005:363) 'language-as-resource' orientation is connected to particular dominant socio-political agendas, namely national security, trade, and law enforcement. He further asserts that these agendas presupposed to benefit the nation as a whole, yet most nations are not neutral with regard to the interests of all languages or groups.

In South Africa, however, we are in the fortunate position that the view of language as a resource is embraced by the government and is instituted in the National Language Policy Framework. But, the orientation does not accord with the perceptions of especially ethnolinguistic groups in South Africa. Black people in South Africa assume that business is indissolubly linked to the English language. It is this perhaps unwitting dichotomizing of English (as a preferred national and international language in commerce and industry) that has circumscribed the viable roles and domains for other languages (at least for the past century) as sub-national, 'ethnic', 'primordial', and secondary other (i.e. local, ethnic, marginal) languages which have tended to undermine the efficacy and scope of the 'language-as-resource' orientation. 
If languages function in particular ways in particular communities, they are in fact resources and should be recognized as such by those communities. Academics and language planners should not conveniently regard them as resources only when they can serve particular disciplinary or state interests, and otherwise ignore or suppress them, whether overtly or covertly. This raises the important question of resources for whom and for what purpose? These are the key elements that require exposition in a fuller accounting of the language-as-resource orientation.

The value of a language and its community of speakers depend on its projected relative value in a particular sector of economic or military activity, rather than on the locally determined interests of the communities themselves. Mainstream economic models of supply and demand fail to consider the role of state planners (or analysts and planners funded by the state) whose interventions in the planning process distort the 'market' in the direction determined by state interests, which change over time. Ricento (2005:349) argues that this means that the geopolitical importance of a language determines its relative market worth as a 'resource'. As noted by Grin (2006:83), there are six forms of market failure that occur where enabling provision for linguistic diversity is concerned, which is sufficient reason for state intervention in language planning and policy.

However, Ozolins (2003:73) notes with disapprobation that some economists seem to be carried away by their theorizing. He cites Choi (2002 in Ozolins, 2003:73) who uses modelling to show that trade restrictions imposed by any country are a clear impediment to the adoption of a universal language. While he admits that such a hypothesis would be difficult to test empirically, Choi confidently assumes that a monolingual trading regime would be the most economically efficient. Not unexpectedly, English is proposed as the best candidate for such a universal language.

The ideas mooted by Lo Bianco (1996:5) are idealistic and serve as an inspiration to secure the survival of languages such as Northern Sotho. Although a shift in economic power may be in progress, English seems to be gaining wider currency and becoming part of the power equation, particularly now that countries such as China and India are showing a decided preference for English. The combined populations of these countries is 2.5 billion; this represents a third of the world's population, to which must be added the 400 million of the predominantly English population of the USA. Global media are overwhelmingly English. The highest, most sophisticated discourse in the widest range of registers has been developed, and is still developing, in English. English feeds into burgeoning communication technologies in the $21^{\text {st }}$ century. One of the natural consequences of the ever-expanding roles for English is that it had increasingly appropriated various centres for itself and can therefore no longer be seen solely as epitomizing older versions of English dominance. Threatened languages should take a cue from the position of English.

The South African National Language Policy is regarded as the most advanced language policy in the world. A newly emergent polity such as South Africa found that it had to designate, de jure, a whole range of languages as 'official languages'. Later it was found that the designation not only failed to solve social and political problems, but rather created a whole range of new ones as well (e.g. how to 'modernize' the chosen languages to connect with global realities).

\section{Aims and objectives}

The primary aim of this study was to determine, and find ways of catering for the specific language needs of business people who would want to use Northern Sotho as a communication medium among themselves when dealing with their clients, or between themselves and their business counterparts, colleagues or subordinates when conducting their day-to-day business as well as to determine ways of establishing Northern Sotho as the language of a 'product' in commerce and industry. Thus the main aims of the study were to:

- investigate the feasibility of using Northern Sotho as a language of commerce and industry in the Limpopo and Gauteng provinces and in other areas where Northern Sotho is spoken 
- determine the need for and feasibility of using Northern Sotho as a language of marketing, advertising and business, and as a language for acquiring entrepreneurial skills (functional elaboration)

- determine whether commerce and industry can provide a conducive atmosphere and construe multilingualism, cultural pluralism and diversity.

\section{Methodological strategy}

A qualitative, explorative, descriptive and contextual design was used to answer the research question. The investigation was characterized by a two-pronged approach to data collection: a questionnaire survey and focus group interviews. A wealth of data was produced by these means. The data from the first phase were captured and encoded in categories set out in frequency tables. The categories were reduced to thematic constructs. Data from focus group interviews were captured and encoded in transcripts that were later decoded and reduced to themes, categories and sub-categories. Although the research design was qualitative rather than quantitative in character, some variables were easy to cast in quantifiable terms. The qualitative method is very important, as it provides an opportunity to solicit the opinions, feelings and attitudes of participants.

This research design involved a sample of 261 randomly selected respondents; 201 responded in the first phase of the study, and focus group interviews were conducted in the second phase. Sixty participants were interviewed of which 44 of the interviewees were mother-tongue speakers of Northern Sotho.

Nine focus group interviews were conducted with 60 consenting and solicited respondents. The focus groups were organized as follows:

- Six groups consisting of six to seven Northern Sotho students each from the erstwhile Technikon South Africa (now merged with the University of South Africa), who were enrolled for a degree or diploma in business, commerce, credit management, marketing, entrepreneurial and small business management as well as office management and technology.

- One group of five Northern Sotho students from the University of Johannesburg who were enrolled for BCom and BCom (Accounting) and BCom (Law) degrees.

- Two groups consisting of eight ANC and APLA ex-combatants each. They spoke a variety of African languages. These respondents were not working at the time and were struggling to find jobs.

The questionnaire survey was based on a multi-stage, stratified, probability sample of 201 carefully selected groups, using a randomizing grid technique. Grounded Theory Techniques (Tesch, 1990:138) of analysing qualitative interview data were used and data were reduced to sub-categories, categories and themes as mentioned before revolving around the following constructs. The:

- exclusive hegemonic use of English or Afrikaans experienced as a communication barrier in commerce and industry.

- socio-economic background of the respondents

- existence of language policies for workers in commerce and industry

- dispositions of mother-tongue speakers of Northern Sotho and other languages towards the prospective development and use of Northern Sotho as a language of commerce and industry

- feasibility of developing Northern Sotho lexicography and terminology for the purposes of commerce and industry.

The question here is how does one determine feasibility? Before this issue could be addressed, another important and sensitive matter had to be considered: to determine whether native speakers of Northern Sotho and other languages are favourably disposed towards the prospective development and the use of Northern Sotho as a language of commerce and industry. The notion is based on PanSALB's language policies guideline of 1998. The relevant passage reads as follows: 
This orientation is consistent with the principle of interdependence, where different communities/ languages are seen to coexist interdependently. The value of each language and its speech community is acknowledged as part of the whole. Language as a resource includes the notion of language as a right. The view that each language is a resource to the nation carries with it the notion of the instrumental use of languages or functional multilingualism.

Hence, the researcher did not exclude respondents from other African language groups and other race groups from the focus group interviews and the questionnaire survey. Mother-tongue speakers of Northern Sotho were in the majority in both instances. The results of the questionnaire survey were supplemented by the focus group interviews. Language planning concepts were discussed since the study deals with the acquisition of a new register/ language (e.g. a business language or a legalese in another context) for use in commerce and industry.

\section{Current language situation in South Africa}

English in South Africa currently occupies the de jure status as a national and international language of commerce and industry, followed by Afrikaans. With such de facto dominance, the unassailed position of English commands respect and power.

South Africa is currently occupying a precarious position within a framework of globalization and internationalization where cultural and linguistic pluralism prevail. There is divergence between South Africa's multilingual language policy on the one hand, and its language practices on the other. The language policy promotes multilingualism, or what Phillipson and Skutnabb-Kangas (1996:429) term an 'ecology-of-language' paradigm, while language practices promote monolingualism (i.e. English or what linguists may term the 'diffusion-of-English' paradigm). With regard to language practices evident in commerce and industry, education, the media and other higher domains it remains true that in South Africa the diffusion-of-English paradigm is gaining momentum in virtually all of the country's institutions even though there are snippets of improvement here and there. Heugh (2000:466) attributes this situation to global societies and the knowledge economy that is being built upon an information highway infrastructure. She argues that the hegemony of the Western free-market economy is such that it influences the economies of developing countries. Western economies tend to be characterized by linguicism, which accords privileged status to English, and a lesser position to other languages. Western aid packages to the developing world have impacted, and continue to impact, on the implementation of language policy. It is important to look at international trends in language policy and their relation to political ideology and free-enterprise economics to assess the implications of implementing new language policy options for business in South Africa. Gellner (1983 in Edwards, 1985:91) asks the global society to consider how important language is, compared to other social factors. Backing this view, Lamberton (2002:14), who is more concerned about the 'language divide' in global society, asks whether language is a matter fit to be explored as a part of economics.

In South Africa, sectors where organic financial growth depends on the speakers of African languages (e.g. financial institutions) function primarily in English. Lack of terminology and funding, as stated previously, are cited as the cause of non-use of the indigenous African languages in South Africa. According to the South African Institute of Race Relations (SAIRR) (1998:40), 75\% of black South Africans are not proficient enough in English to use that language as an effective instrument of economic activity. It would seem economically sensible for banks and other financial institutions to implement multilingualism in their everyday activities and accommodate regional languages. A profile of people who were banking in South Africa in 2002 is reflected in Figure 1 as follows (personal communication with J de Jager, an official at ABSA, on August 11, 2006): 
Figure 1: Language profiles of people who banked with the major South African banks in 2002 (Absa's Archives, Marketing Mix of $1 / 3 / 2002)$

Language profiles in \% -AMPS ${ }^{2}$

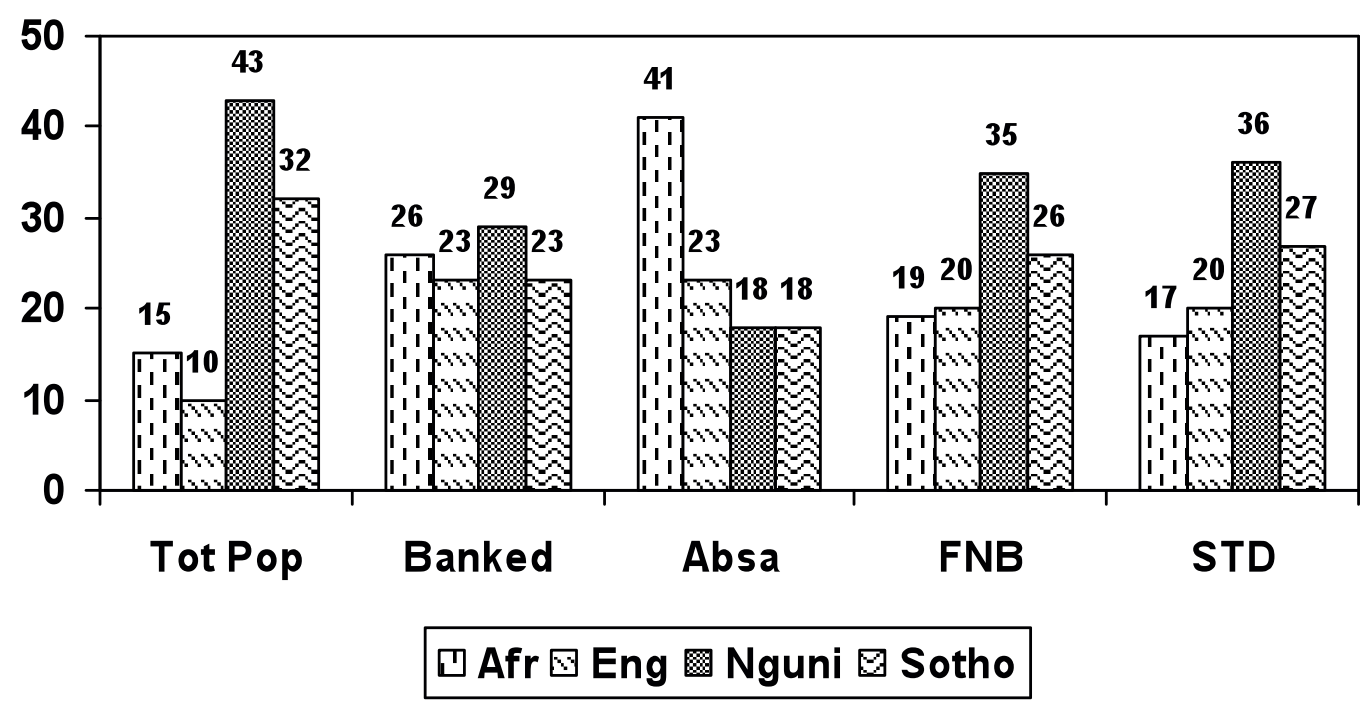

The first group of bar graphs indicators above from the left shows the total population in SA (viz. 2002 figures); the second shows the percentage of South Africans who were banking then. The third to the fifth group indicate language profiles of South Africans who were banking at different banks (viz. Absa, First National Bank and Standard Bank in 2002). Obviously, the picture has changed dramatically since then, but of all these banks only Absa is accommodating all the South African official languages in their quest to provide a better client service. According to an official at Absa, J. de Jager, (personal communication, August 11, 2006) Absa employs multilingualism in its automated teller machines (ATMs). Figure 2 reflects raw data on languages used in ATM machines by Absa's customers.

Figure 2: Absa's national multilingual language usage on ATM machines in $2005^{3}$

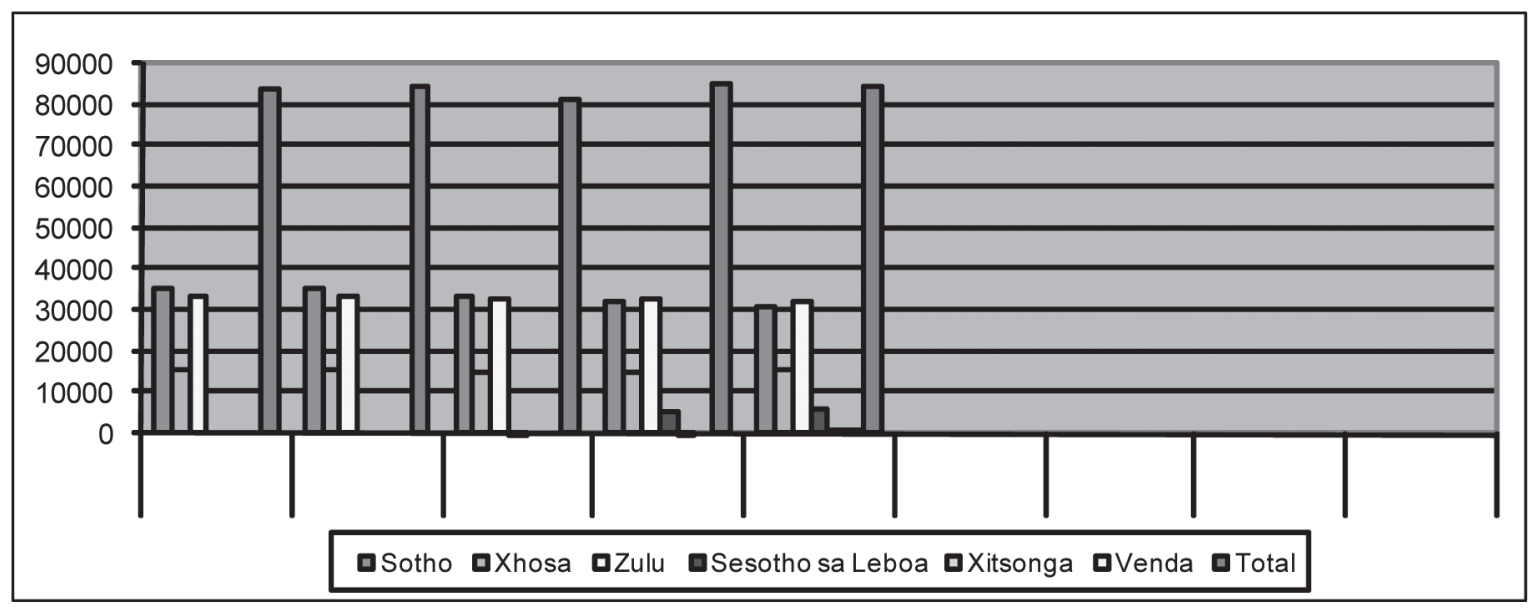

A snippet of Sesotho sa Leboa ${ }^{4}$ appeared in July 2005 and August 2005. There is some doubt about the accuracy of these figures, but they serve as an indication that $\pm 5,000$ Northern Sotho speakers use their language where the choice exists. 
The results of a MarkData ${ }^{5}$ survey conducted on behalf of PanSALB pertaining to languages used by unemployed adults for survival and job-seeking activities are represented in the following chart (PanSALB, 2000):

Figure 3: Language and the informal economy (in \%) (PanSALB, 2000:73)

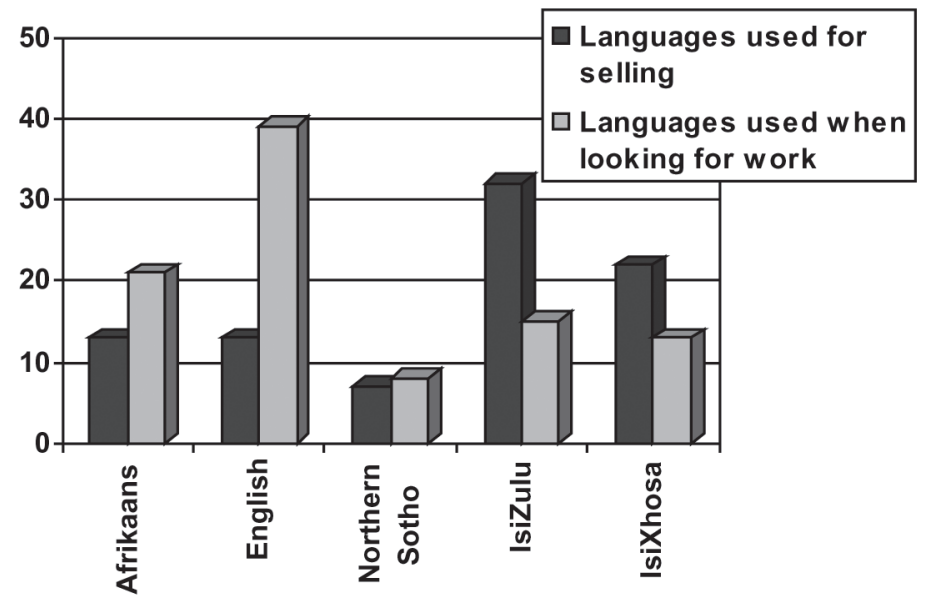

Coulmas (1992:22 in Strauss, Leibertbrandt, Beukes \& Heugh, 1996:3) cautions that unless we understand the economics of language we cannot understand the development of the linguistic map of the world. On the other hand, a proper understanding of economic development is dependent upon recognizing language as an economic factor. This statement has obvious implications for the Northern Sotho speech community in the present context. Grin (1994:39 in Strauss et al., 1996:4) advocates that in future more should be done to employ concepts from environmental economies and to apply cost-benefit analyses to language planning. According to Ozolins (2003:67) economic approaches to language are at odds with the field of language policy/language planning as a result of deficiencies in the literature of both fields. He attributes this misfit to a number of reasons, including the following:

- Economic illiteracy has prevented the recognition of benefits that can flow in some language professional fields (e.g. interpreting).

- Economic considerations dominate the rationale for particular language programmes, but these programmes struggle to realize their economic claims (e.g. programmes promoting the study of using language for economic purposes).

- Issues concerning the use of language for economic purpose arise in international affairs (e.g. international organizations and the regulation of trade).

- Using a language other than the home language to communicate is automatically equated with economic disadvantage and analysed accordingly (e.g. cost-benefit analyses of multilingualism and majority/minority languages).

Grin (1994:34 in Strauss et al., 1996:3) on the other hand states that people who want to do business with one another need to be able to communicate appropriately. An emphasis on language as a tool of communication and a means of information exchange has suggested to some economists that there is an analogy between language and money. One area where economic benefits have often not been recognized has been that of interpreting, particularly in its commonest form, which is liaison interpreting in situations of contact with indigenous or deaf communities, where members of language minorities and the institutions that serve them need a means of communication. Social systems around the world have acknowledged the need for language services, but what is regarded as an adequate service differs widely, and such services have often developed haphazardly. Where governments have assumed a leading role in language planning activities (e.g. South Africa) the onus to provide such language services should lie with or rest on government or/and its agencies. In conclusion, the results of most studies show a positive correlation between language and socio-economic background, particularly in South Africa. 


\section{Research findings}

\section{Phase 1: The questionnaire survey (a quantitative approach)}

The first step towards determining the feasibility of developing and using Northern Sotho as a language of commerce and industry was to determine the current situation in this regard (i.e. situational analysis). The research question was posed to determine which 11 official languages are used most frequently in commerce and industry and in other contexts in the workplace and why. Data about the respondents' indication of the low- to high-frequency use of official languages in commerce and industry is presented in Figure 4 below:

Figure 4: Usage of official languages in business

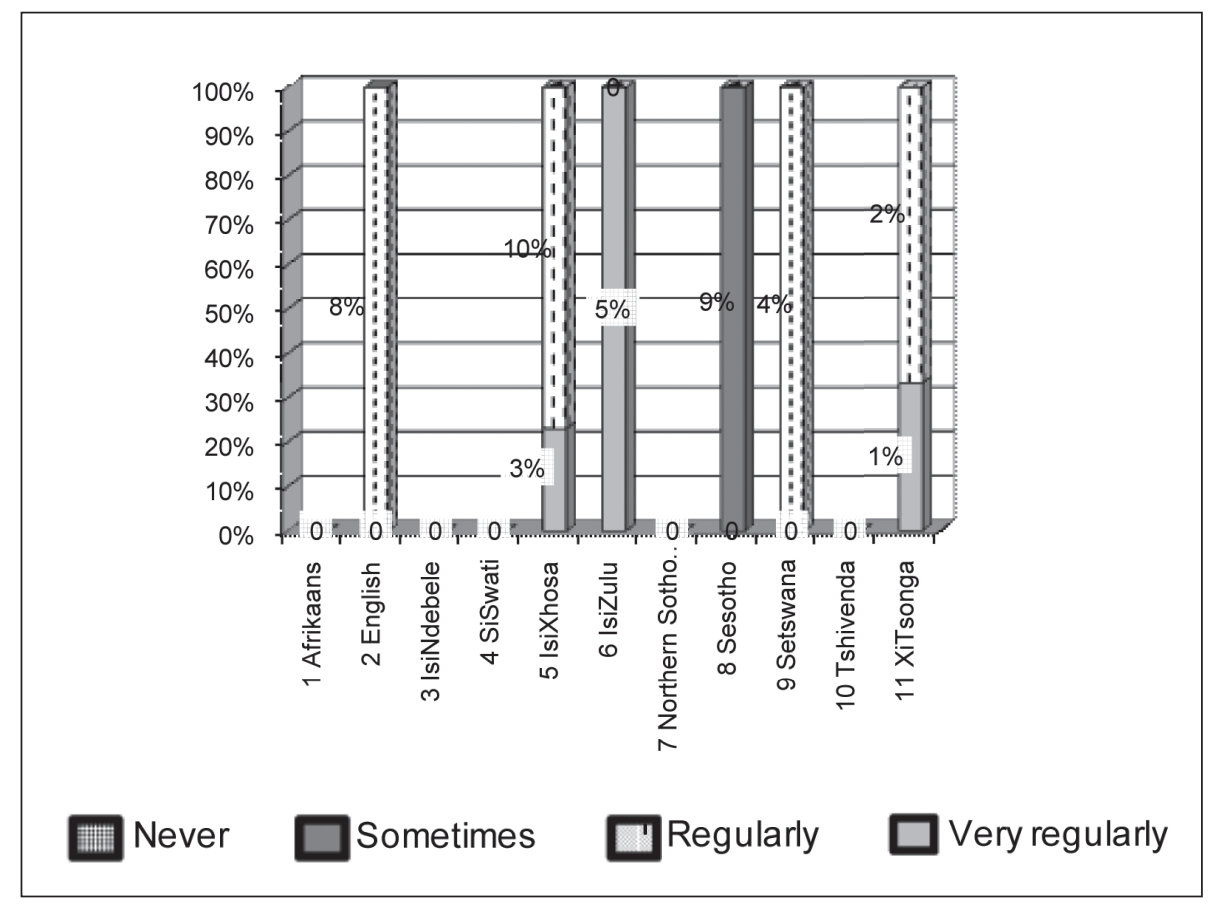

Only $8 \%$ of the respondents reported using English 'regularly', which is to be expected since 90,5\% opted for 'very regularly'. The corresponding figures in this category are $4.5 \%$ for Northern Sotho, $10 \%$ for Xhosa and $12 \%$ for Zulu. A high value is reflected for Zulu under 'very regularly' while other indigenous languages scored $5 \%$, strangely followed by Ndebele and Swati at 3,5\% each. Note that the corresponding number for Xhosa is $3 \%$ while a zero value is recorded for Southern Sotho. Northern Sotho and Tswana each scored 2,5\% in the same category of languages used 'very regularly' internally and externally in commerce and industry. English users in this category amounted to $90,5 \%$ while the corresponding figure for Afrikaans is $21,4 \%$; $16,9 \%$ report occasional use of Northern Sotho, in contrast with $76,1 \%$ who never use it. English at $84,58 \%$ is by far the dominant language in commerce and industry, but whereas only $2,49 \%$ of the respondents professed to be native English speakers here, their proportion is given as $23,4 \%$. Nevertheless, in either case, the figure is placed far below the usage figure. The reason given for this general preference for English (cf. Figure 5 below) is that it is the language they understand best since it is practical and multicultural, and that everyone speaks it.

Reasons for pre-eminence of a particular language in commerce and industry are reflected in Figure 5 below: 
Figure 5: Languages used more often for particular purposes (raw data) ${ }^{6} \mathbf{N}=\mathbf{2 0 1}$

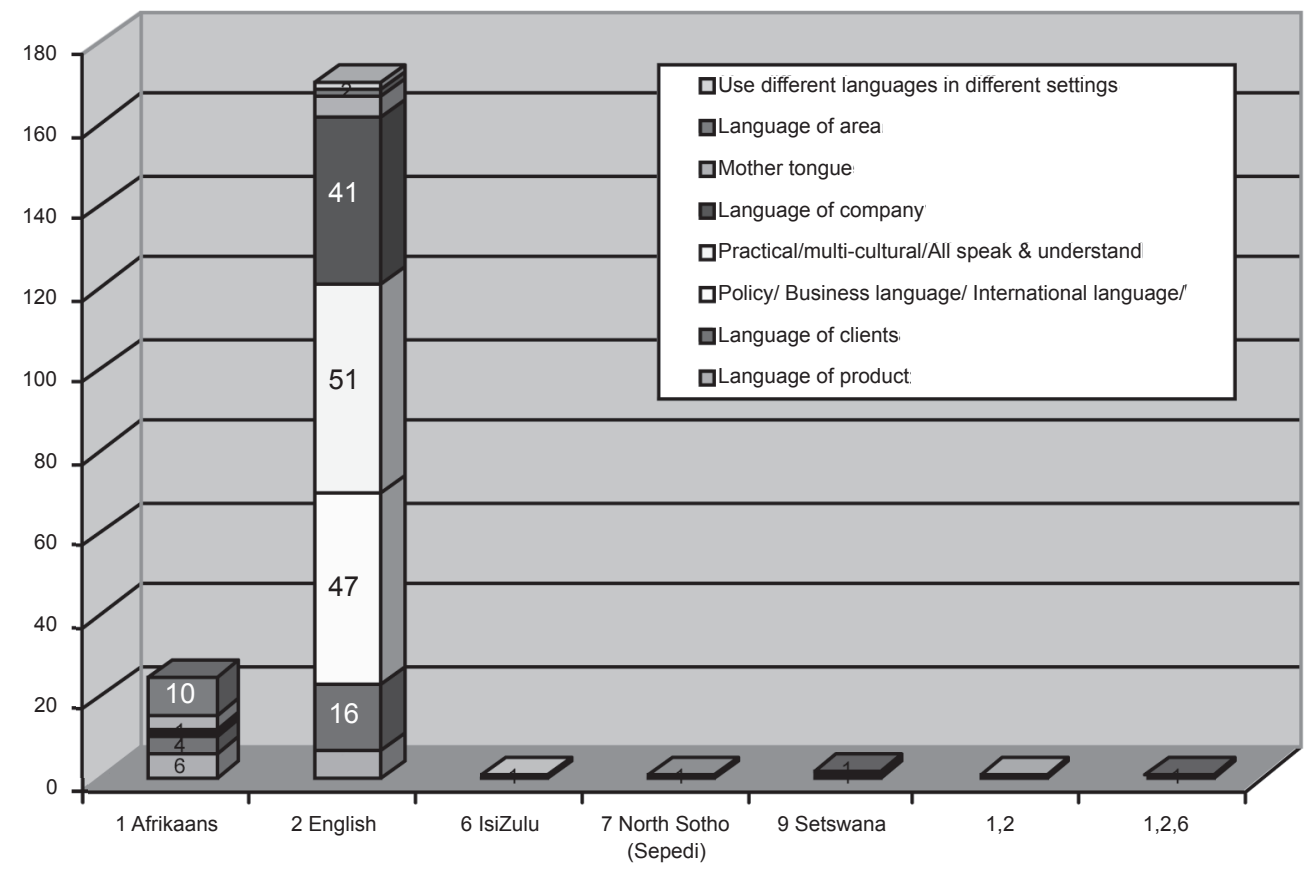

English had a high rating in most of the scores, especially as a language understood by many. It is a prominent choice as a vehicle of policy announcement and a company medium of communication. It is noteworthy that ten respondents indicated Afrikaans as the language of the area, but only one respondent reported that it is the language of the company in category 4, as opposed to 41 who indicated English in the same category. Only one respondent indicated Northern Sotho as a language of product.

The figures below indicate the frequency with which individuals use Northern Sotho in commerce and industry:

Table 1: Respondents who studied Northern Sotho at school

\begin{tabular}{|l|l|l|}
\hline Question 17 (a): Have you ever studied Northern Sotho? \\
\hline & Count & Percentage \\
\hline Yes & 50 & $24,9 \%$ \\
\hline No & 151 & $75,1 \%$ \\
\hline
\end{tabular}

Table 1 was aimed at establishing whether the respondents studied Northern Sotho during or after their schooling years. An overwhelming majority $(75,1 \%)$ of respondents reported to have not studied Northern Sotho at all at school.

Table 2: Frequency of individual usage of Northern Sotho in commerce and industry

\begin{tabular}{|c|c|c|c|c|c|}
\hline & & Frequency & Percentage & Valid percentage & Cumulative percentage \\
\hline \multirow{4}{*}{ Valid } & Moderately or more & 6 & $3 \%$ & $3 \%$ & $3 \%$ \\
\hline & Little & 94 & $46,8 \%$ & $46,8 \%$ & $49,8 \%$ \\
\hline & Never & 101 & $50,2 \%$ & $50,2 \%$ & $100 \%$ \\
\hline & Total & 201 & $100 \%$ & $100 \%$ & \\
\hline
\end{tabular}


The negligible usage reported by $49,8 \%$ seems disproportionate compared to the $24,9 \%$ of respondents who reported that they studied Northern Sotho in Table 1.

The question whether native speakers of Northern Sotho and other languages are favourably disposed towards the prospective development and the use of Northern Sotho as a language of commerce and industry was determined. A negligible percentage of respondents expressed negative sentiments in this regard. A distinct majority (64, 7\%) of respondents who filled in questionnaires were not favourably disposed but a significant minority $(35,3 \%)$ were positive. However, it should be noted that the questionnaire was not designed to reveal explicit allegiances; hence responses in this regard are somewhat open to interpretation.

The respondents indicated that five official languages are actively spoken, formally or informally, in places of employment in commerce and industry. English and Afrikaans are most prevalent. English occupies the de jure status as both `a national and international language in commerce and industry.

Among the five official languages used in commerce and industry, some are used less frequently than others. Afrikaans is reported to be used by $29,4 \%$ and English by $2 \%$. The group concerned obviously works for organizations where Afrikaans is most prevalent. Only $4.98 \%$ of respondents reported Northern Sotho as their least frequently used language. However, this is contradictory since most respondents ticked Afrikaans as the language they use least frequently; $6.97 \%$ of these respondents reported that they use Zulu least frequently. Nevertheless, the usage frequency is higher for Zulu than for Northern Sotho, especially in Gauteng Province.

\section{Phase 2: Focus-group interviews (a qualitative approach)}

In determining the effects of the hegemonic use of English or Afrikaans as languages of commerce and industry it was found that most respondents reported that a lack of proficiency in English prevented them from performing well in their jobs in commerce and industry, and some reported that it had been a significant impediment to their efforts to secure employment. In most instances, they had no option but to use English to interact with potential employers because it was the only language in common use in commerce and industry. After evaluating and assessing a group of unemployed adult learners involved in an Ikhwelo Project, Basel (2004:370) found that English was used as the medium of instruction to teach entrepreneurship and micro-business skills to a group of adult learners.

The writer holds that language and cultural behaviours are often a hidden obstacle to learning for second-language speakers. About the use of English as a medium of instruction, she concluded that individual learners needed good communication skills in order to play an active role in society and participate constructively in the country's economy. Given South Africa's current high unemployment level, education must help learners to think like entrepreneurs and to debate economic issues. It is difficult, however, to think and debate in a language that learners only hear or use in the classroom. The results of the project revealed that at six Ikhwelo centres educators acknowledged that learners had had difficulty understanding the content of theoretical classes and felt that mother-tongue instruction would have improved the learners' results. Both groups of researchers were of the opinion that fluency in English was not a prerequisite for enabling unemployed adults to establish sustainable micro-business ventures in rural areas where English is seldom encountered or required. Wright (2004:177) observes that some South African communities who live in deep rural areas where a traditional language-in-ethno-culture prevails are leading an insular existence that keeps them away from important aspects of modernity.

In determining whether respondents were proficient in Northern Sotho, it was found that $68 \%$ of the respondents had no command of the language while some reported that they were still learning it. This could be the contingent of $17,8 \%$ referred to above since 50,2\% reported that they never use Northern Sotho for purposes relating to commerce and industry. A study called 'Critical mass', commissioned by the South African Broadcasting Corporation, 
crudely measured the percentage of adults' level of comprehension on three competency levels as demonstrated in using a particular language (Van Vuuren \& Maree, 1994 in Webb, 1999:42). The percentages for Northern Sotho and Zulu are given in Table 3 below.

Table 3: Differentiated language proficiency

\begin{tabular}{|l|l|l|l|l|}
\hline & Afrikaans & English & Northern Sotho & Zulu \\
\hline No understanding & $41 \%$ & $31 \%$ & $52 \%$ & $35 \%$ \\
\hline Up to basic level & $25 \%$ & $2 \%$ & $1 \%$ & $2 \%$ \\
\hline Up to intermediate level & $12 \%$ & $21 \%$ & $2 \%$ & $13 \%$ \\
\hline Up to complex level & $21 \%$ & $47 \%$ & $44 \%$ & $49 \%$ \\
\hline
\end{tabular}

(Van Vuuren \& Maree, 1994 in Webb, 1999:42)

Although the linguistic test used in this investigation yielded the above values, the results were dismissed as superficial by other linguists. According to Webb (1999:43), it is highly unlikely that $47 \%$ of the total population of South Africa can use their English skills for any meaningful task beyond 'BICS' (basic interactional skills), such as higher educational development ('CALP': Cognitive Academic Language Proficiency) and for access to the higher domains of life. The $52 \%$ of the respondents who indicated that they do not understand Northern Sotho (cf. Table 3 above) is not too far from the $50,2 \%$ in the research of those who reported that they do not use Northern Sotho at all in commerce and industry or at their places of work.

The researcher also conducted a survey to establish whether language policy documents existed in commerce and industry. The results of the questionnaire survey revealed that 42 respondents were familiar with the language policy or language of the company at their place of work. This was in contrast to all the respondents (in the focus group interviews) who seemed unaware of the existence of such policies in commerce and industry.

From investigating the need to develop and extend targeted/dedicated lexicographic and terminological resources for the use of Northern Sotho in commerce and industry, it was found that most respondents were in favour of developing Northern Sotho terminologies and orthographies for use in higher functions. They suggested that Northern Sotho borrow words from English and use them as loan words instead of starting afresh.

The next step was to look for a model of language acquisition that would suit the communication needs of anyone who wished to acquire a command of Northern Sotho for use in commerce and industry. A model was investigated and recommended.

\section{Recommendations}

The prospects of developing the Northern Sotho lexicography and terminology as a jargon used in commerce and industry and principles of creating a register for use in commerce and industry are critical for this study.

\section{Creation of registers for special purposes}

Language modernization encompasses development of registers and styles for various domains or fields. In this study, the domain envisaged is commerce and industry or the workplace. Suddenly the indigenous African languages have open access to all South African societies, communities and economic activities in which they have never been used before. The question is, 'What approach should be adopted for the corpus development of Northern Sotho?' The approach that should be followed for the development of Northern Sotho should be neither puristic nor anti-puristic, but apuristic. The apuristic approach is informed by the prevailing realities in the context in which the language is used. Other linguists have established that puristic indigenous methods are slow, and that it takes time for such terms to be disseminated to the target users (Madiba, 2000). Loan words should be incorporated 
into the target language with minimum modifications. However, where loan words are adaptable to the linguistic structure of the target language it is advisable to incorporate them with modification wherever possible.

\section{Conclusion}

English and Afrikaans were naturally found to be dominant in commerce and industry while Northern Sotho was used among friends and colleagues in informal situations. Only $3 \%$ of the respondents to the questionnaire survey indicated that they used Northern Sotho for transactional purposes in commercial and industrial settings, while 46.8\% reported using $a$ smattering of Northern Sotho in a variety of situations. The results also revealed that black South Africans in top management positions still prefer English to local African languages. The reasons for black South Africans' language preference is that they associate English with power and success because it provides access to an unparalleled range of knowledge sources and intelligence and is an important language of commerce and industry.

Native speakers of African languages believe that African languages are inherently lacking in the capacity to serve as media of communication for the purpose of higher learning, economic activity, social mobility or any other serious public business. Their only use, they suggest, is as instruments of personal social interaction and cultural expression. According to Heugh (2000:467), the functional use of the African languages will never be fully realized until their potential in economic terms is unmasked. No proponent of multilingualism or local languages has ever suggested jettisoning either the use of an international language or an international curriculum from the education or economic systems of Africa. However, a reconceptualization or recovery of what works well in Africa in terms of the following needs should be integrated into both the education and economic systems that also provide access to the outside world.

Language planning activities designed to limit the hegemony of English should discourage the public perception by South Africans in English-speaking commerce and industry that the 'monolingual habitus' of English is the way to do good business. There are a number of serious problems with regard to a monolingual approach in South Africa. As stated previously, South Africans' knowledge of English, especially in the lower socio-economic strata, is inadequate to function and perform optimally in commerce and industry and participate meaningfully in economic activity. How ordinary indigenous people manage to conceptualize and make sense of the tender documents is puzzling. Webb (1999:179) warns that the exclusive use of English will lead directly to lower productivity and less efficient performance. He lists the problems associated with a monolingual approach as follows:

- The exclusive use of English will lead directly to lower productivity and less efficient performance.

- The exclusive use of English can be very costly, both directly and indirectly. The direct costs involve the money, time and energy that will have to be put into upgrading the general knowledge of English, and the indirect costs involve losses due to misunderstanding, accidents, etc. This is the same issue referred to by Ozolins (2003:73) and Grin (1994:39 in Strauss et al., 1996:4) when they note that in future more should be done to employ concepts from environmental economies and to apply cost-benefit analyses to language planning.

- English can easily become an instrument of exclusion and discrimination. The languages of a country are often embedded in the power relations of the country. South Africa is a good example of this phenomenon: Speakers of non-standard English and non-speakers of English have no power and therefore cannot become profitably involved in a globally controlled economic system. Moreover, the knowledge and skills available through the other languages of the country will be lost.

- The role of language and culture in development, including economic development, is underestimated.

- The exclusive use of English leaves the role of language attitude out of the equation in determining economic performance.

Language planning can make an important contribution to the creation of a better, more just and equitable South Africa. However, if it is to do so, those involved in language planning activities must approach these activities in a less technicist and more democratic way for the good of all South Africans. Multilingualism is not contingent on practicality and expense if it is managed properly. 
South Africa will be best served by a functional multilingual, democratic, ecological language policy. Mühlhäusler (1996:323) notes that an ecological language policy contributes constructively to the ecology of all languages so that all language groups can communicate without neglecting any of the languages used. He reports further that an ecological language policy must create a sustainable environment in which all languages can thrive (instead of only one or two 'powerful' ones). The implementation of an ecological language policy requires long-term goals and language planning.

\section{Notes}

1. Commerce and industry in this context refers to a place of work.

2. AMPS (Absa's Marketing Profile Statistics); Research sources: Absa Archives, Dr Piet Snyman, Renee Roux of Absa Marketing with Strategic Diagnostics, Millward Brown Impact, Mediashop Feb 2002, AMPS research, March, April and May 2002, Marketing Mix of 1/3/2002, Interviews with language specialist in Nedbank, Standard Bank and FNB.

3. Phaahla (2007). Colour representation available: ujdigispace.uj.ac.za:8080/dspace/bitstream/10210/781/1/Thesis 15 April 2007 final editing.pdf.

4. Sesotho sa Leboa and Sepedi are both referred to as Northern Sotho.

5. Privately owned research company in South Africa.

6. Readers who wish to view a colour representation of this figure may email the author.

\section{References}

Basel, B. 2004. Some reflections on the use of English as a medium of instruction in the Ikhwelo Project. Language Matters 35(2):363-375.

Edwards, J. 1985. Language, society and identity. Oxford: Basil Blackwell.

Gordon, R.G., Jr. (ed.). 2005. Ethnologue. Languages of the World. Fifteenth edition. Dallas, Tex.: SIL International. Online version. Available: http://www.ethnologue.com/. Accessed on 2006/05/01.

Grin, F. 2006. Economic considerations in language policy, in An introduction to language policy: Theory and method, edited by Thomas Ricento. London: Blackwell:77-94.

Heugh, K. 2000. The case against bilingual and multilingual education in South Africa. Occasional Paper No. 6. Cape Town: PRAESA (Project for the Study of Alternative Education in South Africa).

Lamberton, D.M. (ed.). 2002. Language: A social technology?, in The economics of language, edited by D.M. Lamberton. Northampton, MA: Elgar:xi-xxvi.

Lo Bianco, J. 1996. Language as an economic resource. Paper presented at a workshop, Pretoria on 14 July 1995. Pretoria: Department of Arts, Culture, Science and Technology.

Madiba, M.R. 2000. Strategies in the modernisation of Venda. Unpublished DLitt et Phil. thesis. Pretoria: University of South Africa.

Mühlhäusler, P. 1996. Linguistic ecology: Language change and linguistic imperialism in the pacific region. London: Routledge.

Ozolins, U. 2003. Language and economics: Mutual incompatibilities, or a necessary partnership? Current Issues in Language Planning 4(1):67-83.

PanSALB see Pan South African Language Board.

PanSALB. 1998. PanSALB's position on the promotion of multilingualism in South Africa: A draft discussion document. October. Pretoria: PanSALB.

PanSALB. 2000. Language use and language interaction in South Africa: Summary report of the national sociolinguistic survey conducted by MarkData on behalf of PanSALB. Pretoria: PanSALB.

Pan South African Language Board. [n.d.] Status language planning. http://www.pansalb.org.za/index. Accessed on 2004/10/06. 
Phaahla, L.P. 2007. Feasibility of Northern Sotho as a language of commerce and industry in the Limpopo and Gauteng Provinces. Unpublished PhD thesis. Johannesburg: University of Johannesburg.

Phillipson, R. \& Skutnabb-Kangas, T. 1996. English only worldwide or language ecology? TESOL Quarterly 30:429-454.

Ricento, T. 2005. Problems with the 'language-as-resource' discourse in the promotion of heritage languages in the U.S.A. Journal of Sociolinguistics 9(3):348-368.

Ruiz, R. 1984. Orientations in language planning. Journal of the National Association for Bilingual Education $8: 15-34$.

SAIRR see South African Institute of Race Relations.

South African Institute of Race Relations. 1998. Fast Facts, July 1998. http://www.sairr.org.za/publications/. Accessed on 2004/09/01.

Statistics South Africa. 2001. Census in Brief: People of South Africa Population Census report No. 03-02-11. Pretoria: Statistics South Africa.

Strauss, G., Leibertbrandt, M., Beukes, E.P. \& Heugh, K. 1996. The economics of language. A workshop on multilinguality and development, held at the University of the Orange Free State on 2 November. Pretoria: Department of Arts, Culture, Science and Technology. Report No.5.2. CTP Book Printers.

Tesch, R. 1990. Qualitative research: Analysis types and software tools. New York: Falmer Press.

Webb, V. 1999. Language in South Africa: The quest for the future: The role of language in the national reconstruction and development. Pretoria: University of Pretoria.

Wright, L. 2004. Language and value: Towards accepting a richer linguistic ecology for South Africa. Language Problems and Language Planning 28(2):175-197. 
Copyright of South African Journal of African Languages is the property of University of Port Elizabeth, Department of African Languages and its content may not be copied or emailed to multiple sites or posted to a listserv without the copyright holder's express written permission. However, users may print, download, or email articles for individual use. 